\title{
Organización de fondos fotográficos en México
}

\author{
Guadalupe Patricia RAMOs FANDIÑO \\ UASLP, San Luis Potosí, México \\ gpramos@uaslp.mx \\ Agustín GuTIÉRREZ CHINAS \\ UASLP, San Luis Potosí, México \\ agchinas@uaslp.mx
}

Recibido: 09/04/2011

Aceptado: 13/05/2011

\section{RESUMEN}

El documento presenta un panorama sobre la organización de los fondos fotográficos de diferentes instituciones en México, tomando como base para su identificación el "Directorio de archivos, fototecas y centros especializados en fotografía", editado por el Consejo Nacional para la Cultura y las Artes (CONACULTA). Registra información sobre datos de identificación institucional, fecha de establecimiento del fondo, área o sección fotográfica, presupuesto, necesidades, personal y su escolaridad. También anota datos sobre las reglas de catalogación y sistemas de clasificación utilizadas para la organización de las colecciones fotográficas, así como la resolución y normas utilizadas para su digitalización.

Palabras clave: Fotografías-Organización. Fondos fotográficos-México. Colecciones fotográficas-México.

\section{Organization of the photographic archives in México}

\begin{abstract}
The paper presents an overview of the organization of photographic archives of different institutions in Mexico, taking as a basis for its identifying, the "Directory of archives, photograph collections and specialized centers in photography" (Directorio de archivos, fototecas y centros especializados en fotografía), published by the National Council for Culture and Arts $($ CONACULTA $)=$ Consejo Nacional para la Cultura y las Artes. Add information about institutional identification data, date of establishment of the fund, or photographic section area, budget, needs, personal and schooling. It also notes data cataloging rules and classification systems used for organizing photo collections, as well as resolution and rules used for scanning.
\end{abstract} Key words:Photograph organization-Mexico. Photograph collections-Mexico.

\section{INTRODUCCIÓN}

La fotografía como documento, ofrece el valor de un mensaje y el valor de sí misma como documento. Es decir, por un lado presenta la posibilidad de reproducir elementos físicos tal cual son por medio de la imagen, lo que le da a la fotografía el valor de la 
representación; y por otro, por el tiempo que transcurre desde su producción, ofrece otro valor de sí mismo como un documento histórico.

Desde el inicio del siglo XX, en algunos casos, la fotografía fue utilizada con fines publicitarios, y aunque en la actualidad ha perdido su valor práctico comercial y propagandístico; se ha transformado en un documento que ofrece información comercial histórica, que además, por el paso del tiempo ha adquirido un valor emocional y estético, que lo convierte también en un objeto de valor artístico.

La fotografía se utiliza para documentar estudios etnográficos, antropológicos y arqueológicos, pero también la fotografía cotidiana, además de dar testimonio de la vida diaria, con el tiempo se convierte en fuente de información para la historia, antropología, arquitectura, técnica, ciencia y la cultura en general; pues es un testimonio visual de la actividad de los seres humanos, porque ofrece un punto de referencia que refleja una realidad social por medio de la imagen, en su medio ambiente natural y artificial.

Por la capacidad que la fotografía tiene para fijar la imagen de una realidad y conservarla como documento para la posteridad, la fotografía se considera como parte del "patrimonio cultural de México". En este sentido, “... la fotografía y el cine intervienen de manera dinámica, efectuando el registro de los acontecimientos diarios y de los hechos sobresalientes. Se documenta la epopeya mexicana. En ese marco se efectúa por primera vez el registro de la configuración social, geográfica y cultural: paisaje y población; arquitectura civil y religiosa; grupos étnicos, y todas las manifestaciones que podían captarse a través de las cámaras fotográficas dejándonos imágenes permanentes que con el correr del tiempo [se convierten] en lo que actualmente denominamos patrimonio cultural. Este patrimonio constituye una de las preocupaciones centrales de instituciones que, como el Instituto Nacional de Antropología e Historia, la Universidad Nacional Autónoma de México y el Archivo General de la Nación, entre otras, tienen entre sus finalidades su recuperación, restauración, clasificación, conservación y difusión."1

Por lo que el objetivo de este trabajo es proporcionar un panorama general de la situación que guardan 71 instituciones mexicanas con colecciones fotográficas, para conocer su distribución en el país, su organización, personal, sus recursos económicos, los servicios que ofrecen y el tipo de usuario que atienden.

\section{METODOLOGÍA}

Para abordar el tema, se tomó como base el "Directorio de archivos, fototecas y centros especializados en fotografia", editado por el Centro de la Imagen de CONACULTA $^{2}$ en el año 2001, y la clasificación propuesta por este mismo Centro.

\footnotetext{
${ }^{1}$ Muñoz Jiménez, Alfonso. El patrimonio cultural de México. México: FCE, 1993. p. 265-272

${ }^{2}$ Masse, Patricia, coord. Directorio de archivos, fototecas y centros especializados en fotografía. México: CONACULTA, 2001. 146 p.
} 
Se diseñó un cuestionario para recoger la información en cada una de las instituciones seleccionadas del directorio anotado en el párrafo anterior. Este cuestionario se compone de preguntas cerradas que engloban tres aspectos. El primero recoge datos de identificación de la institución, su fecha de creación, sección o área que resguarda el acervo fotográfico, presupuesto con que cuenta, suficiencia de sus recursos, necesidades urgentes, así como el número de personal y su escolaridad.

El segundo aspecto que cubre el cuestionario está relacionado con la organización de las colecciones fotográficas y los métodos que se utilizan para esta organización. Las preguntas que se usaron están relacionadas con: colección fotográfica inventariada, tipo de organización para los formatos, las normas de catalogación para la descripción, y el sistema de clasificación para organizar el contenido temático del material fotográfico.

Como tercer aspecto, se consideraron los datos sobre la digitalización de los acervos fotográficos para identificar los objetivos institucionales de la digitalización de imágenes. Para esta parte, se formularon preguntas relacionadas con las resoluciones utilizadas, los formatos de imagen, los archivos obtenidos, las normas de digitalización utilizadas, y el tipo de usuarios de estas colecciones.

El cuestionario se entregó directamente a los responsables de los acervos fotográficos, en la mayoría de los casos. En menor proporción, se mandó por correo electrónico. Además del cuestionario, se utilizó información complementaria que se obtuvo de las publicaciones editadas por las instituciones encuestadas.

\section{Diseño de la muestra}

Para determinar la muestra que representa el universo de instituciones del país que cuentan con acervos fotográficos, se tomó como base para su selección, el método probabilístico estratificado.

La característica de este método, es que en un principio, todos los elementos de la población tienen la misma probabilidad de ser elegidos, de tal suerte que los elementos de la muestra tienen valores muy aproximados a los valores de la población total, ya que las mediciones de los subconjuntos, serán estimaciones muy precisas del conjunto mayor.

Esta precisión depende del error de muestreo llamado también error estándar. Y para la cual, en esta investigación se asignó un margen de error del 10\%. Para la muestra probabilística se determinó primero el tamaño de la muestra, para luego seleccionar sus elementos de forma aleatoria. El tamaño de la muestra se calculó con base en la varianza de la población, que se obtuvo con el cuadrado del error estándar. En tanto el error estándar sea menor, el tamaño de la muestra será mayor. Una vez determinado el tamaño de la muestra se eligieron aleatoriamente los elementos muestrales, utilizando el procedimiento de selección por tómbola, que consiste en numerar todos los elementos muestrales del $l$ a la $n$, para hacer una ficha por cada elemento, revolverlas en una caja, 
e ir sacando las fichas, según el tamaño de la muestra. Los números escogidos al azar, conforman la muestra. ${ }^{3}$

\section{Instituciones seleccionadas}

En la siguiente tabla, se expone el universo de instituciones que se divide en subconjuntos, de acuerdo con la clasificación institucional a la que pertenecen. La proporción se determinó con el cuadrado del error estándar. La proporción de instituciones en la muestra, indican el número de instituciones por clasificación que se estudiaron, y por último, el total de instituciones que representa la muestra, que en este caso es de 71 instituciones.

\begin{tabular}{|l|c|c|c|}
\hline \multicolumn{1}{|c|}{$\begin{array}{c}\text { Clasificación de } \\
\text { las instituciones }\end{array}$} & Universo & Proporción & $\begin{array}{c}\text { Proporción de } \\
\text { instituciones en } \\
\text { la muestra }\end{array}$ \\
\hline $\begin{array}{l}\text { 1. Archivos estatales y } \\
\text { municipales }\end{array}$ & 18 & $13.33 \%$ & 9 \\
\hline $\begin{array}{l}\text { 2. Colegios, Centros } \\
\text { de Estudio, Institutos } \\
\text { de Investigación, } \\
\begin{array}{l}\text { escuelas y } \\
\text { Universidades }\end{array}\end{array}$ & 24 & $17.78 \%$ & 12 \\
\hline 3. INAH & & & \\
\hline $\begin{array}{l}\text { 4. Archivos } \\
\text { Fotográficos y } \\
\text { Fototecas }\end{array}$ & 13 & $9.63 \%$ & 7 \\
\hline 5. Centros Culturales & 5 & $5.93 \%$ & 2 \\
\hline $\begin{array}{l}\text { 6.Centros de } \\
\text { Información y } \\
\text { Documentación }\end{array}$ & 3 & $3.70 \%$ & 3 \\
\hline $\begin{array}{l}\text { 7.Cinetecas y } \\
\text { Filmotecas }\end{array}$ & 2 & $2.22 \%$ & 1 \\
\hline 8. Mueso y Galerías & 15 & $1.48 \%$ & \\
\hline 9. Archivos Privados & 7 & $11.11 \%$ & 1 \\
\hline 10. Bibliotecas & 2 & $5.19 \%$ & 1 \\
\hline 11.INEGI & 1 & $1.48 \%$ & 6 \\
\hline $\begin{array}{l}\text { 12. Agencias y Bancos } \\
\text { de Fotografía }\end{array}$ & 26 & $19.26 \%$ & 13 \\
\hline $\begin{array}{l}\text { 13. Otros, que no } \\
\text { entraron en ninguna de } \\
\text { estas categorías }\end{array}$ & 11 & $8.15 \%$ & \\
\hline
\end{tabular}

${ }^{3}$ Hernández Sampieri, Roberto, et al. Metodología de la investigación. 2 ed. México: McGraw-Hill, 1998, p. 207-213. 


\begin{tabular}{|l|l|l|l|}
\hline Total & \multicolumn{1}{|c|}{135} & & 71 \\
\hline Error & $10 \%$ & Diferencia de los & \\
& & resultados & \\
& & muéstrales y & \\
& & poblacionales. & \\
& & Es el nivel de & \\
& & seguridad de que & \\
& & los resultados & \\
& & muéstrales dan & \\
& & estadísticamente & \\
& & correcta sobre la & \\
& & población se & \\
& & acostumbra 90, & \\
& & 95 o 99\%. & \\
\hline Nivel de confianza & $90 \%$ & & \\
\hline Proporción & $50 \%$ & & \\
poblacional & & & \\
\hline
\end{tabular}

\section{Análisis de la encuesta aplicada}

En este apartado se analizan las respuestas dadas a cada una de las preguntas incluidas en el cuestionario que se aplicó durante la encuesta, a las diferentes instituciones participantes, cuyos resultados son los siguientes:

\section{Nombre de la institucion, departamento, sección, área}

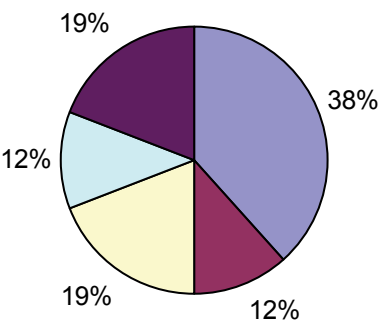

Otros

Los acervos fotográficos en las instituciones presentan diferentes denominaciones, aún cuando muchos de estos acervos pertenecen a una sección o área de una misma institución, no existe uniformidad en los nombres, 38\% utiliza el nombre de fototeca, $19 \%$ de ellas fondo grafico y archivo fotográfico respectivamente, así como un $12 \%$ acervo fotográfico y el $12 \%$ restante colección fotográfica, archivo iconográfico, centro fotográfico, centro de la imagen y en otras ocasiones, la sección o área lleva el nombre de un fotógrafo o el del primer fondo que se les incorporó. 


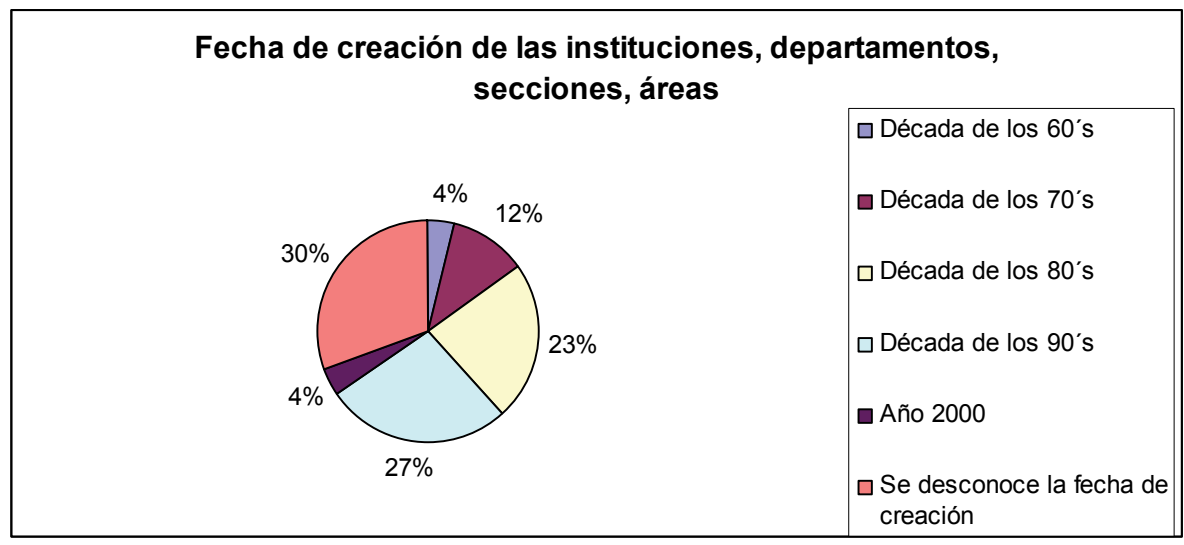

En este rubro se percibe que el $30 \%$ de las instituciones desconocen la fecha concreta de su creación. Es común que los acervos estuvieran inicialmente a cargo de personal que ya no labora en la dependencia, y que no dejaron registro de creación de la sección, departamento o área. Es importante observar cómo en las décadas de los ochentas y noventas, las instituciones reflejan una preocupación por los acervos fotográficos, ya que el $23 \%$ y $27 \%$ de las instituciones reportan haber creado espacios específicos para este tipo de acervos. En la década de los sesentas y setentas solo fueron creadas el $4 \%$ respectivamente.

\section{Necesidades urgentes de la institución}

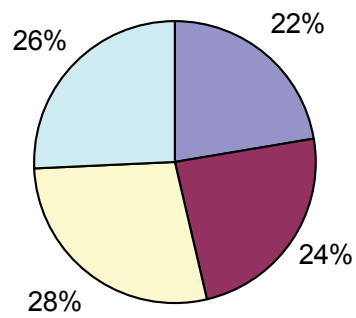

Espacio fisico

$\square$ Recursos humanos

$\square$ Recursos económicos

$\square$ Equipo de computo

Las necesidades más urgentes de las instituciones, para la organización adecuada de sus colecciones fotográficas se reflejaron en las siguientes cifras: El 28\% de las instituciones manifiesta requerir de recursos económicos, el $26 \%$ equipo de cómputo, el $24 \%$ requiere de recursos humanos y el $22 \%$ de más espacio físico. 


\section{Número de personal encargado del acervo fotográfico}

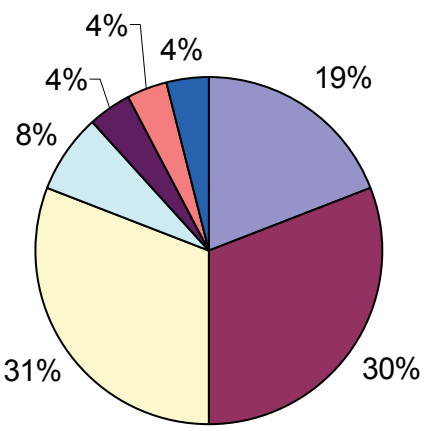

$\square$ Uno

$\square$ Dos

$\square$ Tres

$\square$ Cuatro

$\square$ Cinco

$\square$ Catorce

Veinticinco

El 31\% de las instituciones declara que sólo cuenta con tres personas encargadas del acervo fotográfico, el $30 \%$ con dos, el $19 \%$ con una, el $8 \%$ con cuatro, y el $4 \%$ con dos, catorce y veinticinco.

A excepción del Sistema Nacional de Fototecas (SINAFO) del INAH y del Centro de la Imagen de CONACULTA, instituciones que manejan sólo imágenes fotográficas, en las instituciones restantes, el personal encargado del acervo fotográfico realiza más actividades dentro de las instituciones, por lo que la organización de las colecciones fotográficas sólo es una más de todas las tareas que realiza este personal.

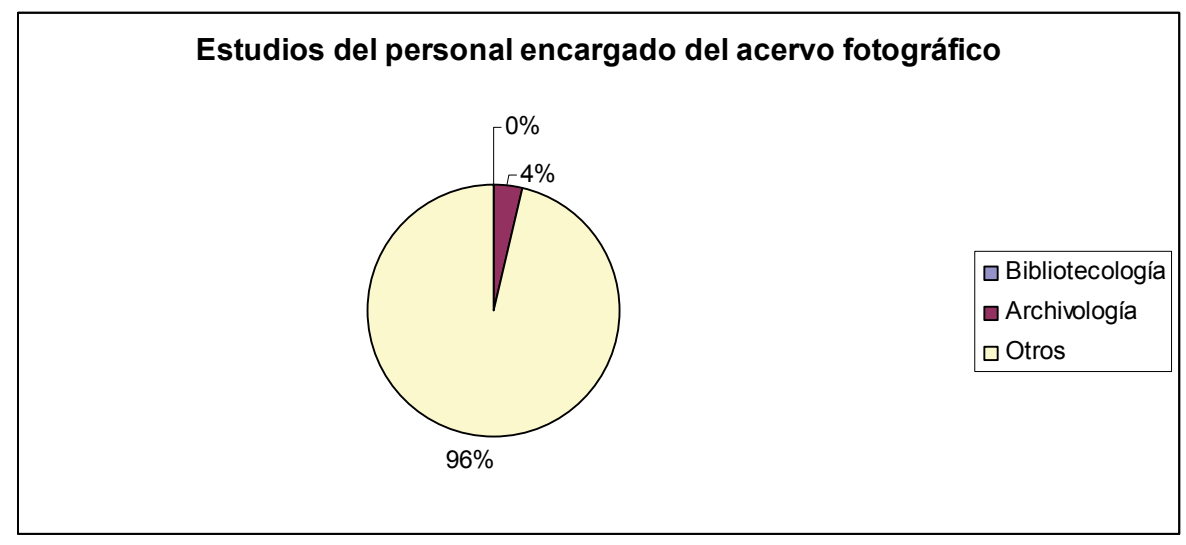

En ninguna de las instituciones encuestadas trabaja personal con formación en bibliotecología. Solo un 4\% cuenta con formación en archivología y el 96\% cuenta con otros estudios, entre los que destacan historiadores, fotógrafos, etnólogos, filólogos, 
contadores, ingenieros en sistemas, periodistas y personal con estudios mínimos de preparatoria.

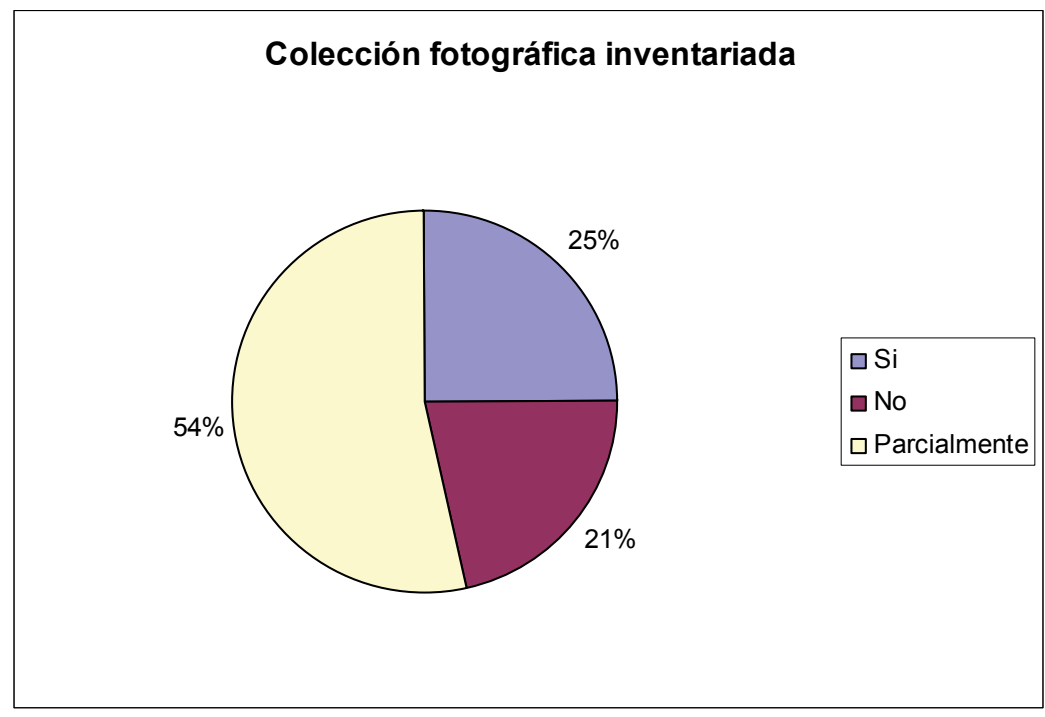

\section{Organizacion del acervo fotográfico}

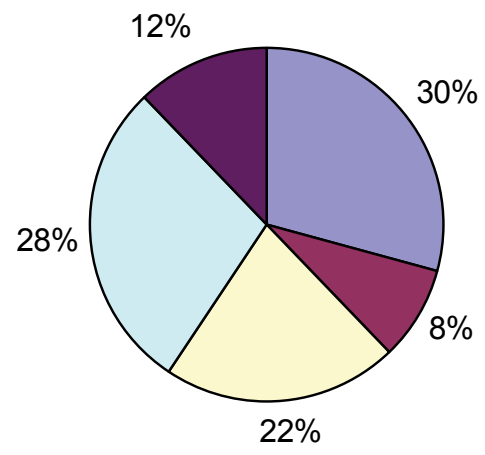

$\square$ catalogado

$\square$ clasificado

$\square$ catalogado y clasificado

$\square$ inventariado

no indican nada

Aún cuando el inventario debe ser la primera parte de la organización y de control de la colección, el 54\% de las instituciones sólo tiene parcialmente inventariadas sus colecciones, mientras que el $25 \%$ cuentan con un inventario completo y el $21 \%$ no cuentan con inventario. 
E1 $29 \%$ de las instituciones indican que únicamente tienen catalogado su acervo fotográfico, $7.5 \%$ indican tenerlo únicamente clasificado, $24 \%$ catalogado y clasificado, $5 \%$ únicamente inventariado y $6.5 \%$ no indica nada.

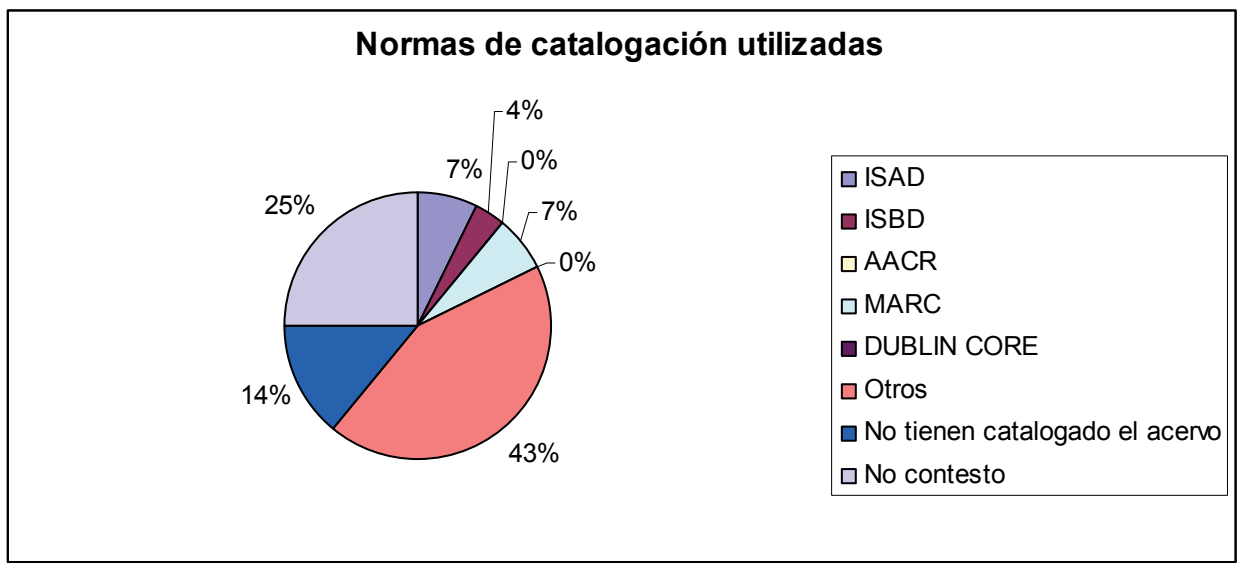

Con relación a las normas de catalogación utilizadas por las diferentes instituciones, ninguna de ellas menciona utilizar Dublín Core o las Reglas de Catalogación Angloamericanas. El 4\% utiliza las ISBD, el 7\% utiliza ISAD y MARC respectivamente, el $43 \%$ menciona utilizar normas de catalogación creados por la misma institución, en las que mezclan normas basadas en las reglas internacionales de catalogación. El $14 \%$ no tiene catalogado el acervo y el $25 \%$ no contestó a esta pregunta.

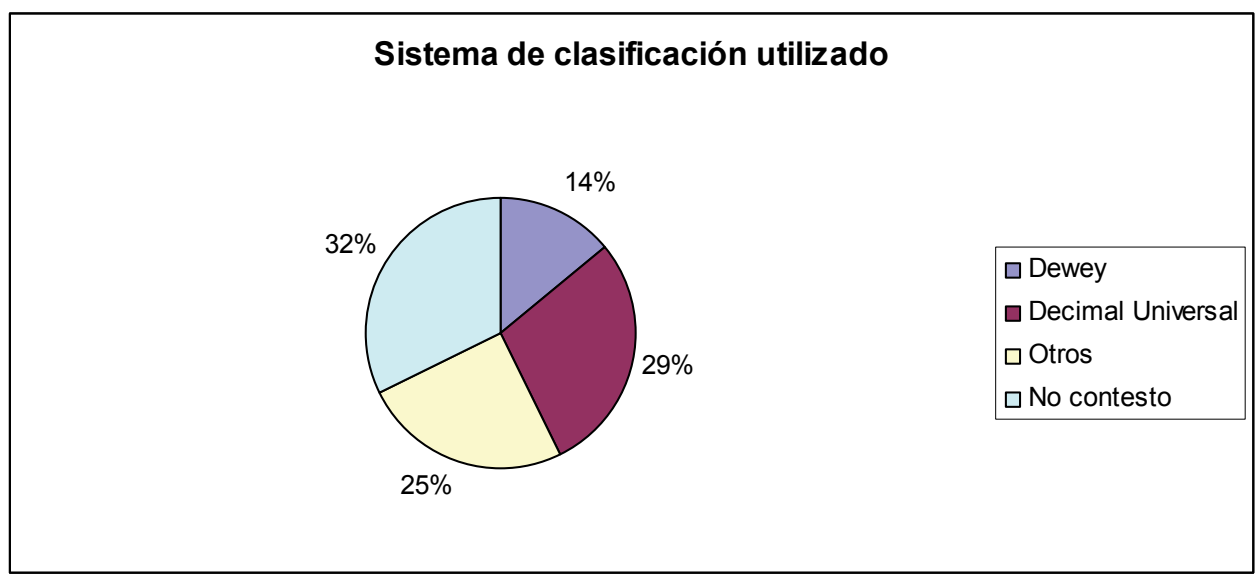

A diferencia de las normas internacionales de catalogación, las instituciones tienen más conocimiento de los sistemas internacionales de clasificación, ya que un $14 \%$ de las instituciones menciona utilizar el Sistema de Clasificación Decimal Dewey, un 29\% 
el Sistema de Clasificación Decimal Universal, el 32\% de las instituciones menciona utilizar otros sistemas de clasificación adaptados de los sistemas universales, y en su mayoría los sistemas propuestos por el SINAFO.

\section{Se digitalizan las fotografias}

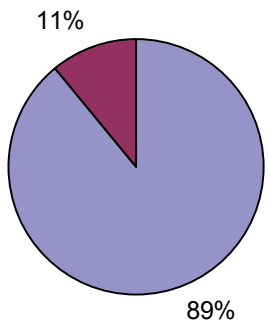

Como se puede observar en esta gráfica, la mayoría de las instituciones mexicanas reflejan una preocupación por la digitalización de las fotografías, pues el $89 \%$ de las instituciones encuestadas las tiene digitalizadas, mientras que un $11 \%$ no digitaliza sus fotografias.

\section{Formatos en los que se realiza la digitalización}

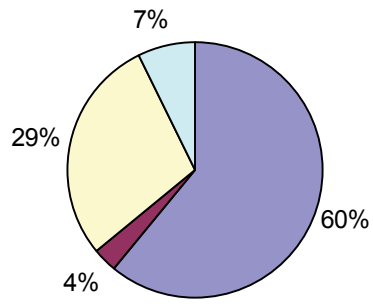

En México, la mayoría de las colecciones albergadas en las diferentes instituciones son de reconocido valor histórico, por lo que resulta interesante conocer los formatos sobre los cuales se realiza la digitalización de las imágenes. El 60\% de las instituciones menciona realizar la digitalización sobre los originales, el $29 \%$ sobre originales y reproducciones, el $4 \%$ sobre reproducciones y un $7 \%$ no contestó la pregunta. 


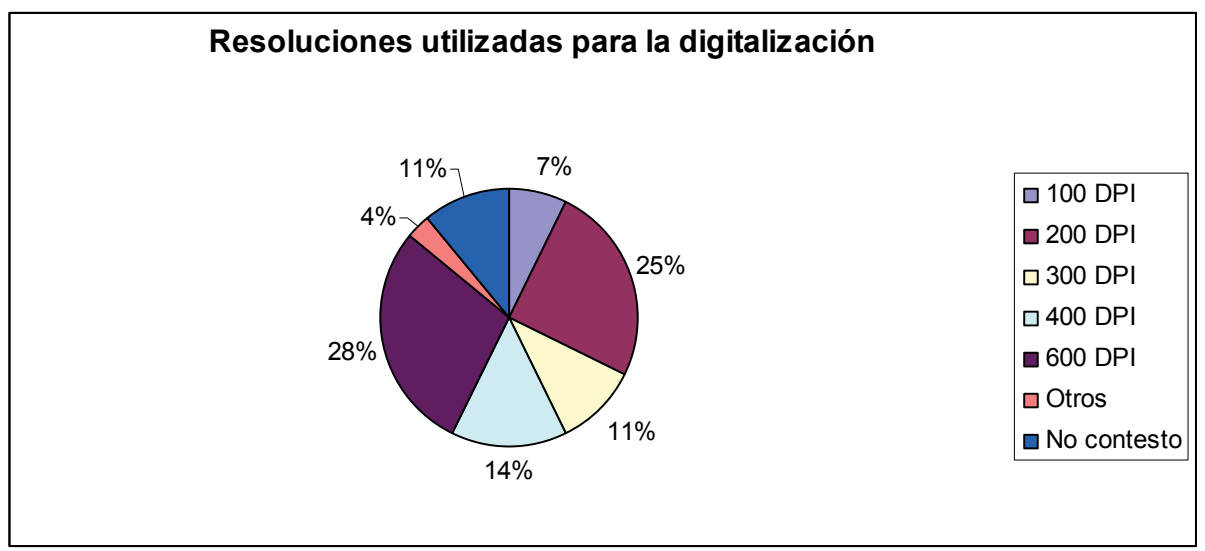

La calidad de las fotografías digitalizadas depende de la resolución con la que haya sido realizada la digitalización. Al aumentar la resolución, la calidad de la imagen se conserva, lo ideal para fines de difusión y reproducción es la resolución de 600 DPI (Dots per inch). En México el $28 \%$ de las instituciones estudiadas utiliza la resolución de 600 DPI, el 25\% 200 DPI, el 14\% 400 DPI, el 7\% de 100 DPI, el 11\% de 300 DPI, el $4 \%$ mencionó utilizar otro tipo de resoluciones y $11 \%$ de las instituciones no contestó la pregunta.

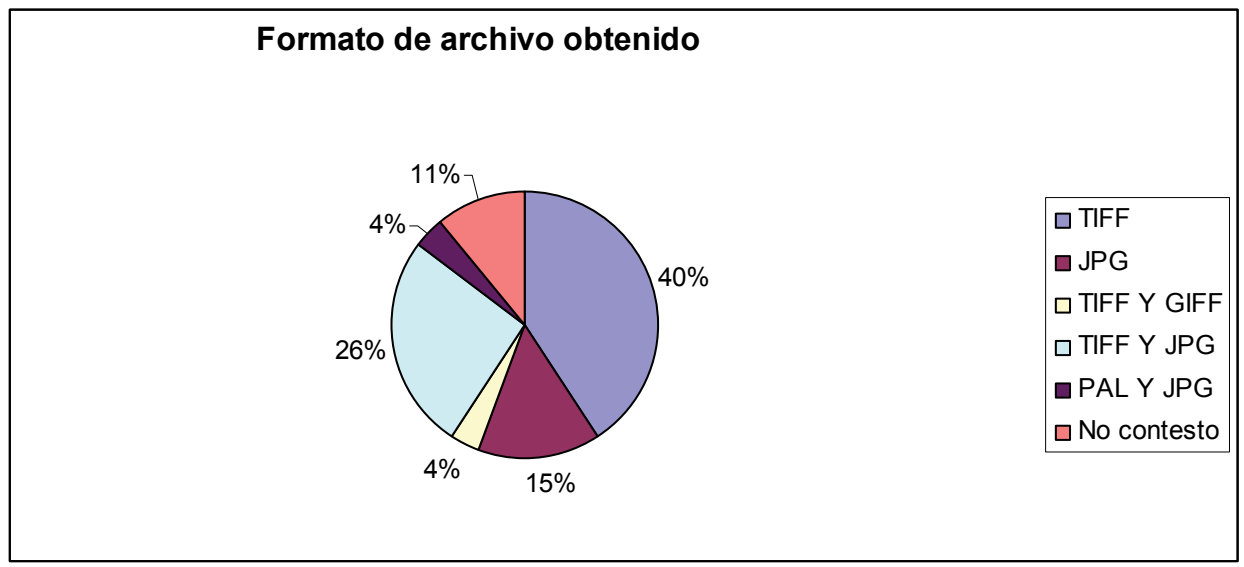

Los formatos de archivo electrónico obtenidos deben estar definidos de acuerdo a los objetivos de la digitalización. Para las copias de imágenes con fines de conservación, es recomendable el formato TIFF (Tagged Image File Format) que produce imágenes de alta calidad, mientras que el formato JPG (Join Photographic Expert Group) realiza copias con pérdida de calidad, pero fáciles de transmitirse por Internet. De la población estudiada el $40 \%$ de las instituciones utiliza el formato TIFF, 
el 26\% TIFF y JPG, el 15\% PAL (Phase Alternating Line) y JPG, el 4\% TIFF y GIFF (Graphic Interchange Format), y un 11\% de las instituciones no respondió a la pregunta.

\section{Utilizan normas para la digitalización}

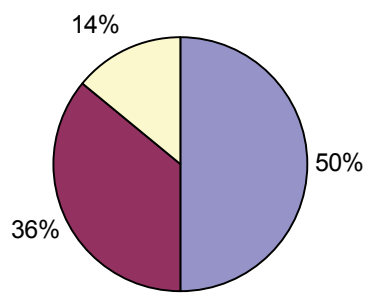

$\square \mathrm{Si}$

$\square$ No

$\square$ No contesto

Aún cuando el 50\% de las instituciones encuestadas menciona utilizar normas de digitalización, ninguna menciona las normas utilizadas para tal actividad, mientras que un $36 \%$ menciona no utilizarlas y un $14 \%$ no contestó a la pregunta.

\section{Existe un catálogo automatizado para la consulta de las colecciones}
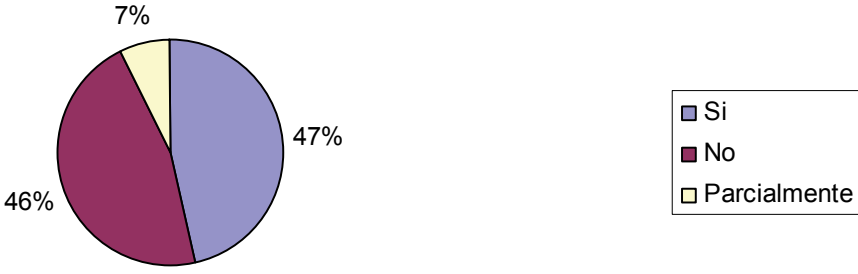

Las gráficas anteriores muestran que el $89 \%$ de las instituciones tiene digitalizadas sus fotografías. Sin embargo, el $46 \%$ de las mismas no cuenta con un catálogo automatizado para la consulta de las colecciones, un $47 \%$ menciona que si, mientras que un $7 \%$ sólo cuenta con catálogo automatizado parcial, por lo que se puede decir que gran parte de estas instituciones no tienen claro los objetivos de la digitalización, o sólo lo hacen con fines de conservación de las imágenes. 


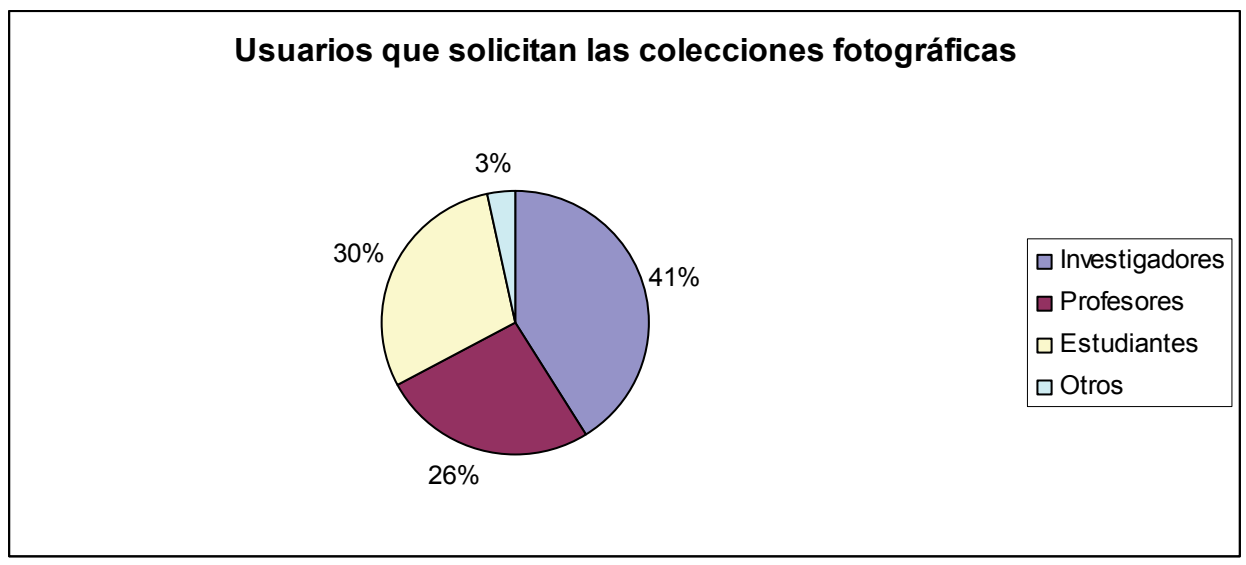

Esta gráfica muestra qué usuarios son los que utilizan con mayor frecuencia las colecciones fotográficas. El $47 \%$ de los usuarios son investigadores, y en su mayoría historiadores, un $30 \%$ estudiantes de posgrado, un $26 \%$ profesores como apoyo a la docencia y un $3 \%$ otros usuarios relacionados con la industria editorial.

\section{CONCLUSIONES}

En México existen diferentes formas en los nombres adoptados por las instituciones para nombrar las secciones o áreas que albergan sus acervos fotográficos, planteando un problema denominativo y conceptual, sin que hasta ahora exista un acuerdo entre las instituciones sobre el nombre apropiado a adoptar. Con relación a la fecha de establecimiento de la sección o área en las instituciones, creadas para la organización de los acervos fotográficos, se puede observar que son recientes y que han surgido como una de las nuevas necesidades de integrar las imágenes como fuentes documentales para la investigación, así como también para la docencia y la divulgación.

Los resultados presentan una realidad de carencia acentuada de recursos económicos, humanos y materiales en las instituciones encuestadas, con excepción del SINAFO y del Centro de la Imagen, que fueron creados ex profeso para la organización, conservación y difusión de las imágenes.

En su mayoría, las instituciones cuentan con muy poco personal y sin formación y capacitación en organización de información documental. Por carecer de recursos económicos necesarios para la capacitación del personal en su campo de trabajo, se tiene una repercusión negativa en la organización de los acervos, pues no se cuenta con profesionistas con la formación necesaria para esta actividad, a pesar de que en México existen 8 escuelas en el área de bibliotecología y dos en archivología. Los egresados no son captados en estas instituciones, quienes en su mayoría se desempeñan en instituciones académicas o en la iniciativa privada.

Con relación a la organización de los acervos fotográficos, este proceso no se concluye en ninguna de sus etapas. Una muestra lo constituye la mayoría de las 
instituciones que sólo tiene parcialmente inventariado, catalogado y clasificado su acervo. En cuanto a la catalogación, es frecuente que las instituciones desarrollen sus propios códigos de catalogación con un porcentaje mínimo de elementos descriptivos, lo cual hace que se tengan muy pocos puntos de acceso para la recuperación. Por lo general el trabajo de descripción consiste en la catalogación y pocas veces se realiza la clasificación y la indización de los materiales gráficos. Así mismo, un alto porcentaje utiliza el sistema de clasificación propuesto por el SINAFO, respetando siempre en esta clasificación la procedencia de los acervos.

La mayor parte de las instituciones encuestadas realizan la digitalización de su acervo fotográfico, aunque no está claro cuáles son los objetivos de esta actividad, ya que aún cuando mencionan contar con catálogos automatizados, éstos no se encuentran al servicio de los usuarios, por lo que se puede decir que esta actividad no está relacionada con fines de difusión. Así mismo, un alto porcentaje de estas instituciones menciona utilizar normas de digitalización, sin embargo no contestaron cuales son las normas utilizadas, por lo que se desconoce si la digitalización solo se realiza con fines de conservación de los acervos, o si tiene otros propósitos.

Para concluir, es importante señalar que la fotografía se convierte cada vez más en una fuente de investigación documental para la historia, pues un alto índice de usuarios de estos acervos son historiadores, pero también es necesario indicar que la fotografía es utilizada, cada vez más, como apoyo para la docencia y la investigación por los estudiantes de posgrado.

Con el propósito de insistir en la necesidad e importancia de la organización y conservación de este material documental, se incluye como epílogo de esta exposición, los siguientes pensamientos recogidos en ilustraciones anónimas, que fundamentan el papel testimonial del documento fotográfico en la vida social, en los siguientes términos:

"La fotografía... es el arte de pintar con luz. También es la máquina del tiempo, por la forma en que nos lleva al pasado.

Es el vehículo más rápido, una imagen nos lleva a un lugar.

Es un detonador de emociones. Es la explosión del color ó la síntesis del blanco y negro.

Nos muestra un pasado cercano o distante, nos cuenta una historia.

Hay expresión y emoción en una imagen. Nos dice algo...

Es un instante de tiempo congelado en la memoria.

Nos muestra movimiento, emoción, nos cuenta una historia o nos transmite una acción.

Actitud, color, intención, detalle...

Ninguna otra forma de expresión artística es tan contundente, tan profunda, tan exacta, tan cruda, o tan emotiva como una fotografía..." 


\section{BIBLIOGRAFÍA}

GARZA MERCADO, A.Manual de técnicas de investigación para estudiantes de ciencias sociales. 6 ed. México: El Colegio de México, 2005. 410 p.

HERNÁNDEZ SAMPIERI, Roberto. Et. al. Metodología de la investigación. $2^{\mathrm{a}}$ ed. México, McGraw-Hill, 1998. 501 p.

MASSE, Patricia, coord. Directorio de archivos, fototecas y centros especializados en fotografia. México: CONACULTA-Centro de la Imagen, 2001. $146 \mathrm{p}$.

MUÑOZ JIMÉNEZ, Alfonso. El patrimonio cultural de México. México: FCE, 1993. p. $265-272$

SCHMELKES, C. Manual para la presentación de anteproyectos e informes de investigación; tesis / Corina Schmelkes. 2 ed. México: Oxford University, 1998. 205 p.

ANEXO 1. Cuestionario aplicado

Este cuestionario es para un estudio que servirá para elaborar una investigación acerca de la situación de los Archivos Fotográficos en México. Solicito su ayuda para que conteste unas preguntas que no llevaran mucho tiempo. Sus respuestas serán confidenciales y anónimas. Todos los datos recabados serán incluidos en la investigación, con excepción de los datos individuales.

1.- ¿La Institución cuenta con presupuesto propio?

$\mathrm{Si}$ ( ) No ( )

2.- ¿Son suficientes los recursos económicos con los que cuenta la Institución?

$\mathrm{Si}$ ( ) No ( )

3.- ¿Cuáles son las necesidades más urgentes de la Institución?

Espacio físico ( )

Recursos humanos ( )

Recursos financieros ( )

Equipo de cómputo ()

Otros ( ) Especifique

4.- Número de personal encargado del acervo fotográfico:

5.- El personal encargado del acervo fotográfico cuenta con estudios de:

Bibliotecología ( )

Archivología ()

Otros ( ) Cuáles

6.- ¿La colección fotográfica se encuentra inventariada?

Si ( ) No ( ) Parcialmente ( ) 
7.- ¿Cuál es el método utilizado para inventariar las colecciones fotográficas?

Número consecutivo ( )

Otros ( )

9.- Las colecciones fotográficas están organizadas por:

Nombre del fotógrafo ( )

Por tema ( )

Por número de registro ( )

Por número de clasificación ()

Por procedencia o colección ()

Por formato ( )

Otra forma ( ) especifique

10.- Las normas de catalogación utilizadas para la descripción del material fotográfico son:

$\operatorname{ISAD}()$

$\operatorname{ISBD}()$

$\operatorname{AACR}()$

$\operatorname{MARC}()$

DUBLIN CORE ( )

OTROS ( ) ESPECIFIQUE

11.- El sistema de clasificación utilizado para las colecciones fotográficas es:

DEWEY ( )

DECIMAL UNIVERSAL ( )

CLASIFICACIÓN LC ( )

OTROS ( ) ESPECIFIQUE

12.-Los formatos en los que se encuentran las colecciones fotográficas son:

Positivo ()

Negativo ()

Diapositiva ( )

Otros ( ) Especifique

13.- ¿Se digitalizan las fotografias?

$\mathrm{Si}$ ( ) No ( )

Si su respuesta es si, pase a las preguntas $14,15,16,17,18$, si la respuesta es no, pase a la pregunta 19.

14.- La digitalización se realiza a partir de:

Originales ( ) reproducciones ( ) 
15.- ¿Qué resoluciones se utilizan para la digitalización?

100 DPI ( )

200 DPI ( )

400 DPI ( )

600 DPI ( )

Otros ( ) Especifique

16.- Los formatos de imagen utilizados son:

Blanco y negro ( )

Niveles de gris ()

Color ()

Otros ( ) Especifique

17.- El formato de archivo obtenido es:

TIFF ( )

GIF ( )

PAL ()

Otros ( ) especifique

18.- ¿Utilizan normas para la digitalización?

$\mathrm{Si}$ ( ) No ( )

19.- ¿Existe un catálogo manual o automatizado para la consulta de las colecciones? Si ( ) No ( )

20.- ¿Qué tipo de usuarios solicitan las colecciones?

Investigadores ( ) Indique el área:

Profesores ()

Estudiantes ( )

Otros ( ) 